\title{
Estimating The Limits of Stability under Several Working Conditions at Experimental Turning
}

\author{
Ramiz Saeed Matty Samarjy
}

Assistant lecturer

University of Mosul- College of Engineering- Mech. Engineering . Department

\begin{abstract}
Predicting the Self-Excited vibrations (Chatter) during the cutting process as a result of the interaction between the cutting tool and work - piece is important as a guide for the cutting machine user for an optimal selection of the back engagement of tool in work piece(depth of cut), the rotational Speed for the specific feed rate which will produce maximum chip removal with out these undesirable vibrations. Such undesirable vibrations can spoil the cutting surface with chatter marks, which will have adverse effects on the whole cutting system. This can be achieved by performing several experimental researches. In the present study, a cutting process was performed by using the slide feeding of Hindustan lathe machine and sintered carbide inserts to cut several cylindrical shafts of $32 \mathrm{~mm}$ in diameter and $70 \mathrm{~cm}$ long steel AISI1050 with out using coolant lubrication to specify the stability limits that represented by curves with the rotational speeds which separate stable and unstable zones for maximum productivity and accepted surface roughness. Also study the effect of feed rate upon the stability and the amplitude of vibration for constant depth of cut and rotational speed.
\end{abstract}

Key words : stability limit, chatter vibration, self excited vibration

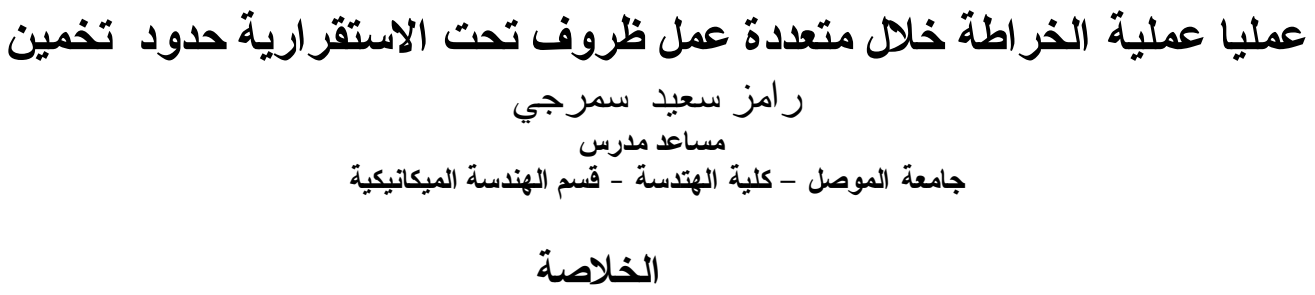

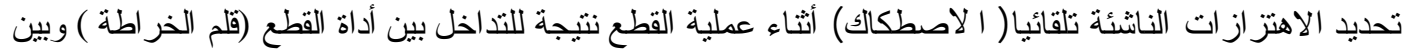

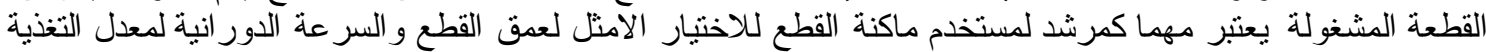

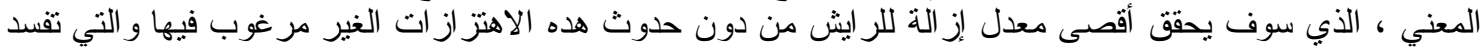

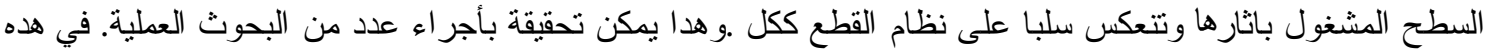

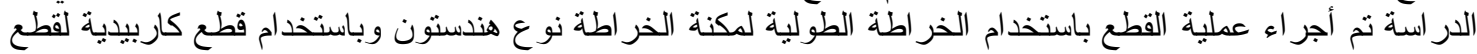

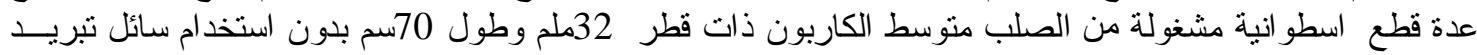

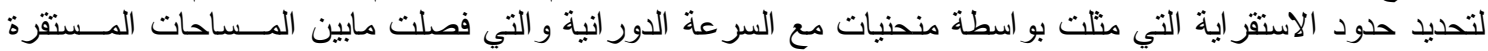

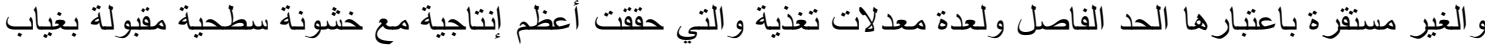

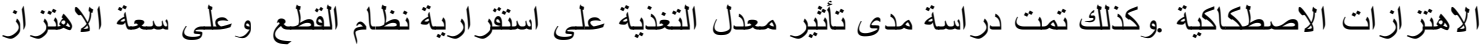

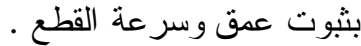
الكلمات الدالة : حد الاستقر ارية ، الاهنز از ات الناشئة تلقائياً ، الاصطكاك 


\section{Al-Rafidain Engineering $\quad$ Vol.17 $\quad$ No.6 $\quad$ Dec. 2009}

\section{Introduction}

High feed rate and large work piece tool engagements in machining operation may often be limited because of unwanted instability namely " chatter " that refers to the vibration which exists between tool and work piece which will spoil the work surface with pattern of irregularities and violent oscillation .When it is so severe, it can stop the cutting process, damage the tool, work piece, change the cutting conditions, and...etc . Methods available for predicting the boundary of stability , being complex, are seldom used on the shop floor. For large volume production, the stable machining conditions can be obtained through experiments [2].Many variables affect the machining stability such as ,structural stiffness, damping, tool geometry, cutting speed, feed rate, depth of cut, fluid lubrication, hardness of material to be cut, transfer vibrations from the grounding of work shop and others. The vibrations initiating through the cutting process either forced or self excited. The amplitude of vibration delay the disturbing force by phase shift angle. Forced vibrations are most often caused by cyclic variations in cutting forces. Also chatter can occur in machining operations where cyclic variations in cutting force not normally present as in our approach ( turning of plain cylindrical shafts),This type of chatter is difficult to predict the conditions under which it occurs [4].Self - induced vibrations can arise in two ways . First , when the process is basically unstable so that any slight displacement of tool relative to work piece rapidly builds into large amplitude vibration. This condition is commonly referred to as negative damping. Secondly when the process is more complicated but common. Here the cutting process is basically stable, and vibrations are caused by some sudden relative work piece tool displacement which decays as the cut progresses. However with most practical cutting operations, overlapping cuts are taken,and when the tool removes the chatter marks left during the previous revolution of cut, ,forced vibration occur increasing the amplitude of vibration and is referred to as

( regenerative chatter) fig ( 1 ) $[3,4]$.The most worst state is when the two surface waveness are out of phase by 180 degree. Our approach is an attempt to find an experimental correlation which connect the cutting speed and the limit of tool engagement at the threshold of unwanted chatter using the Indian turning machine tool of the mechanical engineering department, college of Engineering Mosul university through machining many of medium carbon steel shaft pieces. Also to show the effect of feed rates on the cutting stability in addition to how the cutting speed affects the vibration of the toolwork piece interaction.

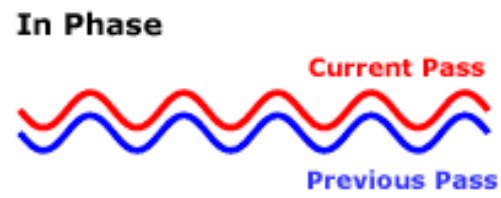

Out Of Phase $\left(180^{\circ}\right)$

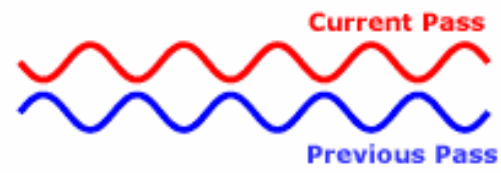

Fig (1) stable and unstable condition when cutting a current and subsequent cut on a wavy surface(regenerative chatter vibration) 


\section{Experimental Investigation}

Machining tests were carried out by the orthogonal turning without lubrication . Medium carbon steel AISI1050 (85HRB) was cut into $70 \mathrm{~cm}$ long test specimens (shafts) with $32 \mathrm{~mm}$ in outside diameter, performed on Hindustan center Lathe LB20 which has the following specifications as given in its manual catalogue [5].Distance through centers (60$1500 \mathrm{~mm})$,straight bed, main spindle speeds $(32-1600 \mathrm{rev} / \mathrm{min})$, longitudinal or sliding feed (0.05-1.4 mm/rev), cross feeds (0.03-0.93 mm/rev),max. horse power(10hp). This arrangement is used with a tool grade sintered carbide insert type $41605 \mathrm{w}$ with holder(Sandvik coromant Sweden hr 111-2020(150p30) in tool geometry $(5.75 * 14.5 * 8.5 \mathrm{~mm})$ with ( 8 ) deg Flank angle and (12)deg rake angle, tool overhang $(30 \mathrm{~mm})$. The cutting conditions that are selected in determining the stability limits for slide turning are the main spindle speeds $[250,320,400,640,800 \mathrm{rev} / \mathrm{min}]$, the feed rate $[0.1,0.2,0.4,0.6,0.8 \mathrm{~mm} / \mathrm{rev}]$. while these used for studying the regenerative effects are the same as the ones mentioned above addition to $(0.1 \mathrm{~mm})$ depth of cut. The intensity of vibration was picked by accelerometer type 4339 Bruel and Kjear with the current and voltage sensitivity $(1 \pm 1 \%)$ and $(1 \pm 2 \%)$ respectively for a frequency range $0.2-12000 \mathrm{hz}$, resonance frequency $35 \mathrm{khz}$ [1] fixed to tool holder and close to cutting edge.

The stability zones were plotted on the coordinate system defined by depth of cut and rotational speed instead of cutting speed .Experimental Rig shown in fig ( 3 ), accelerometer probe fixed at a point on the tool holder close to cutting point by a distance of $20 \mathrm{~mm}$ to picke up the vibration amplitude of tool in the feed direction, which feed to the hand-held integrating vibration meter type Bruel \&Kjear 2513 to measure and display the vibration level in RMS value (ISO 2954) in terms of the velocity amplitude using the wiring connection and power source (3 battery 1.5v) [1]. Also the Light microscope ( unionme -3125) is used to investigate the microstructure of shaft material (medium carbon steel $0.5 \%$ Carbon ). Fig (3) represents the microstructure of work piece used in this study which is enlarged from 100x on the negative to $250 \mathrm{x}$ on the printed picture .

The accelerometer picked vibration intensity for about (14) points on the cutting machine tool body under no cutting conditions to re adjust any loosening by tightening the bolts and nuts, belts ,..etc that give undesirable responses as much as possible .

During this approach the cutting was accomplished on many pieces of shafts $(70 \mathrm{~cm})$ long each partitioned into three segments named from the tailstock in direction towards the headstock (-0 $0-25 \mathrm{~mm}, \bullet 25-45 \mathrm{~mm}, \boldsymbol{\Delta} 45-65 \mathrm{~mm})$.

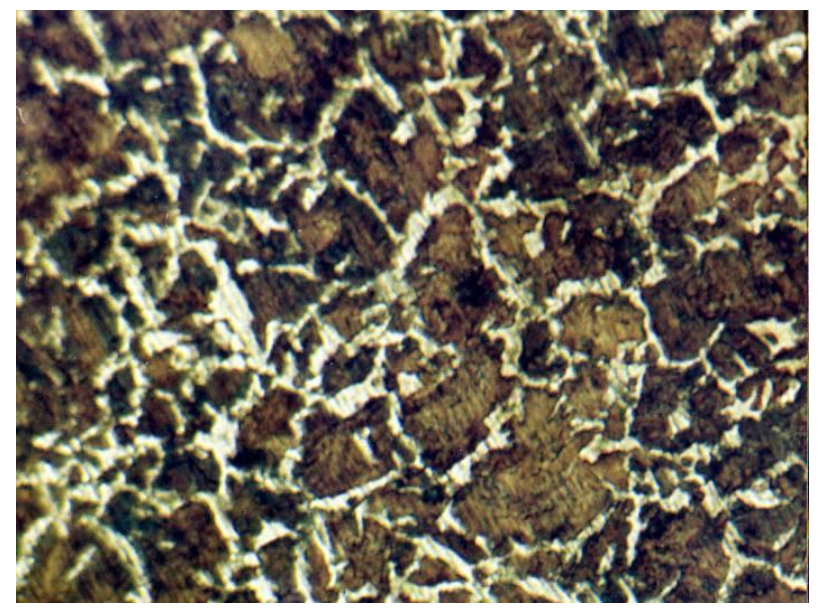

Figure (2) The Microstructureof Steel Shaft (250X) . 
Al-Rafidain Engineering $\quad$ Vol.17 $\quad$ No.6 $\quad$ Dec. 2009

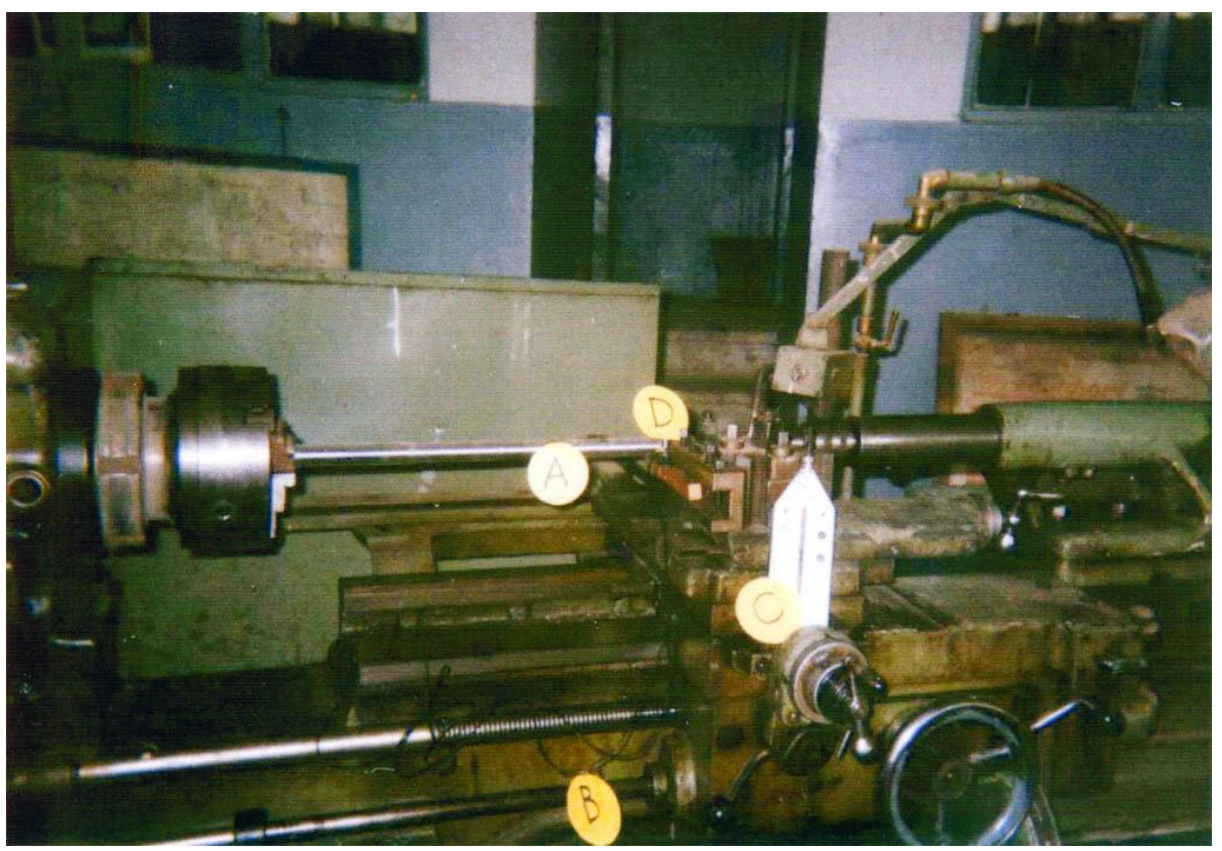

Figure ( 3 ) Experimental Test Rig For Data Collection as Connected with Machine
A: Work piece.
B: Connecting Wire
C: Integrating Vibration Meter Type Bruel \& Kjaer
D: Accelerometer Type Bruel \& Kjaer.

\section{Influence of feed rate on the limit of stability}

The effect of feed rate upon the limit of stability at a constant speed generally shows that the stability limit decreased with increasing the feed rate for the specified speed ,as shown in figures (4.a,4.b,4.c,4.d,4.e).An increase in stability was clear at high speed( see fig 4.e).

\section{Influence of cutting speed on the limit of stability}

A typical stability lobe is the function of spindle speed and machining .Thus, the borderline of stability that represents the back engagement (critical diagram, which predicts system depth of cut) is a function of speed for a given tool geometry, was obtained by drawing a curves for specified feed rate to distinguish stable from unstable cutting conditions. The lowest value of critical depth of cut indicates the asymptotic depth of cut at which stable cutting conditions exist for all speeds.

Figures (5.a,5.b,5.c,5.d,5.e)represent these relationships. So in our attempt we regard three variables which influence the cutting stability among accompanied variables assumed to be constant or which have less effects for facilitating this study and focusing upon the influence of variables that can be controlled and changed .

Reducing speeds is a popular method of chatter suppression [2]. From this aspect if we follow the obtained curves we see that this aspect was verified for speed up to ( $400 \mathrm{rev} / \mathrm{min}$ ) ,but the stability starts to increase with increasing speed, This is belonging to tool geometry which first assumed to be fixed but in reality play a role effects in the subsequent cuttings that lead to a change in clearance and rake angles. Clearance angle changes during cutting as a result of grinding the tool after a period of work. The borderline shape ( $\mathrm{L}$-shape) that 
connect the concurrent points of lobes confirming to that obtained by (Liu) who studied the effect of tool geometry on stability limits of the machining system [3 ].

To improve the system stability, controlling the relative displacement of the tool with respect to the work piece, is a good solution which does not reduce the productivity but requires expensive control equipments.

The chatter vibrations produce characteristic sound and superficial marks. These marks can be observed by visual inspection of the work piece. So such a received pattern is due to little overlapping of the cutting tool through the interaction with work piece during the cut. So, the undulations performed in previous and subsequent cutting surfaces, differ by phase shift. When cutting on such a wavy surface to remove the chatter marks left during the previous revolution, the cutting tool will submit to a periodic disturbing force in nature which has a frequency equal to the natural frequency of the cutting tool or its holders ,

The tool holder can be represented by a cantilever configuration with a rectangular cross - section with a point loaded at the end. The natural frequencies ( $\mathrm{rad} / \mathrm{s})$ of vibration are given by [9].

$$
\omega_{n}=\beta_{n} \sqrt{\frac{E l}{\rho A}}
$$

where $\beta_{n}$ : is the end condition parameter which depend on the length of the overhang $(l)$ and for the first mode it is given by,

$$
\beta_{1}=1.875104 / l
$$

$\mathrm{E}$ : the modulus of elasticity of the cantilever, $l$ : the second moment of area of the shank cross-section, $\mathrm{n}$ : is the mode of vibration , $(\rho)$ : the mass density of tool holder material.

Aforced vibration occurs because of variations in the tool force, This vibration can result in an increasing amplitude of vibration called a regenerative chatter. The system of cutting process is now in resonance and the displacement of cutting tool will delay $\left(90^{\circ}\right)$ in its phase beyond the disturbing force which create such a pattern ( fig 1 ).Also we can say that any variations in the undeformed chip thickness are sensed by the cutting tool in advance to its position .In the other words , the fluctuations in tool forces (measured at the tool cutting edge ) lead to fluctuations in the undeformed - chip thickness by an amount equal to the horizontal projection of the shear plane ( geometric phase shift ). Fig 7 shows the severity of chatter, and explains the differences between chatter and feed marks .

\section{Influence of feed rate on vibration amplitude at constant cutting speed and depth of cut :}

From figures (6.a,6.b,6.c,6.d,6.e) it can be observed that the fluctuating level of vibration amplitude at cutting speed (250rev/min) for different feed rates is restricted around a closed value along three selected partitions of the shaft under study indicated in fig (6.a), but Generally rising when cut with ( $\mathrm{F}=0.8 \mathrm{~mm} / \mathrm{rev})$.and the second partition of shaft record Generally rising as compared with others .

As the speed increased, noticeable increasing of the amplitude levels up to $(3.5 \mathrm{~mm} / \mathrm{sec})$ when cutting with (320rev /min) fig (6.b).

Fig (6.c) shows an increasing in the vibration amplitude with increasing feed when cutting with (400 rev/min).

To sum up:-

1-The feed rates have an effect in increasing the vibration amplitude at low speeds :as the speed increases the amplitudes get down which agree with the fact of (B.U.E).It means that when cutting the ductile material with low speeds , the cutting surface will have considerable surface finish and as the cutting tool advances the work piece material will be compressed as 


\section{Al-Rafidain Engineering $\quad$ Vol.17 $\quad$ No.6 $\quad$ Dec. 2009}

it closely approaches the cutting edge and the plastic state will be reached, plastic flow will be achieved along the cutting tool surface after passing the cutting zone with continuous chip formation but when the cutting speed gradually increases, the temperature rises, and work piece will suffer high strain after the fracture will occur .With more increasing cutting speed the chip fracture will disappear and the (BUE) will be seen clearly coherents to cutting tool surface for transient period of time. After an additional increase in speed, (BUE) will disappear .It means that the appearance of BUE is due to high resistance to relative motion between the chip and cutting tool face .With considerable increase in the speed, it will disappear and the vibration amplitudes will get down and the current cutting processes will stabilize more than the pervious ones. The cutting with a second part of the shaft for a distance $(25-45 \mathrm{~mm})$ rises the vibration amplitude as a result of deflection which seems to be clearly near the close points to fixing positions.

2- generally we cannot adopte a general standard behavior of feed effects upon the vibration amplitude, and at a small amount of depth of cut the vibration will be quite enough to separate the cutting tool form its engagement to work specimen during a period of time for each revolution.

3-B.U.E produces discontinuous chip resulting in periodic fluctuating in the cutting force and its frequency represents the cutting agent which may be equals to the frequency of cutting tool or its carriers. At this moment the self excited vibrations will occurs, the severity of these vibrations is of importance at the resonance initiation on which it depends .

a - cutting speed and cutting force. If the cutting speed is coincident with the harmonic speed of the cutting tool or its holder at natural frequency $(\omega / 2 \pi)$, effective cutting force will be greater. With the direction of rotation of the work piece. And a considerable work will be done on the vibratory system for each cycle. When this energy is more than the energy lost due to friction ,amplitude of vibrations will increase (negative damping ), but this amplitude may be limited at that moment and the cutting tool frequency will be larger than the work piece speed. The friction force between the cutting tool and the work piece will reduce the power demand from motor which create positive damping that inhibits an increase in the amplitude of vibration.

b - wear in face or surface of tool clearance adds additional disturbances and negative damping .

Also must refer to the unhomogeneity of the steel structure ,fig ( 2 ).

Pearlite is more concentrated in some zones, the random distribution of cell sizes affects the increasing amplitude of vibration.

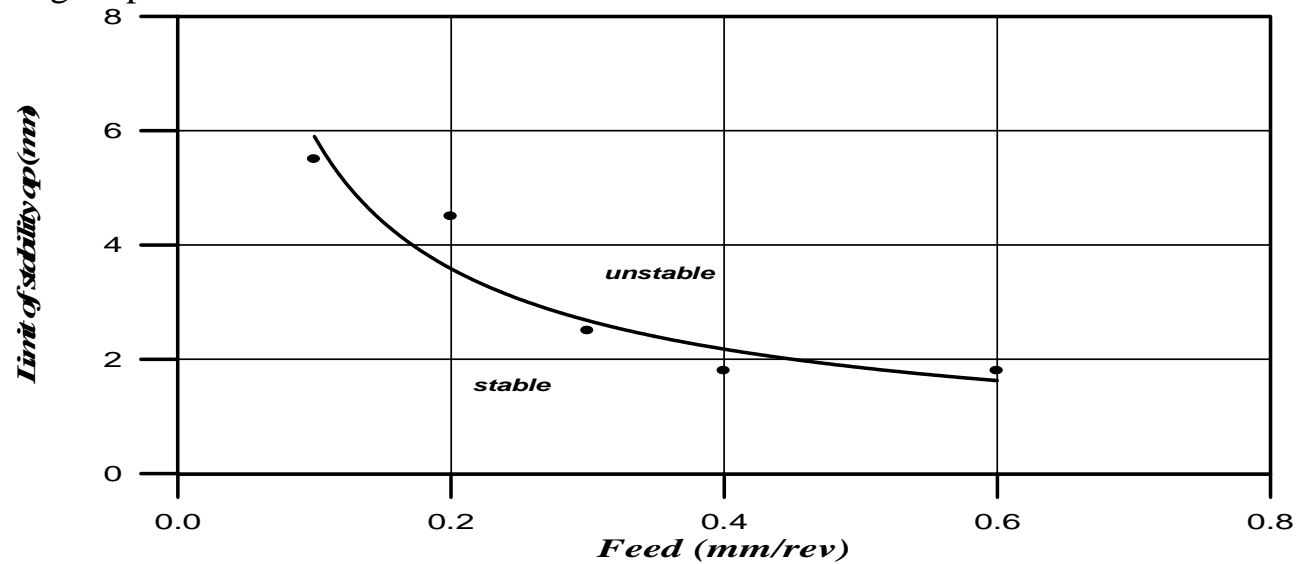

Fig ( 4-a ) the effect of feed rate on the stability limit through cutting the steel with speed (250 r.p.m) 


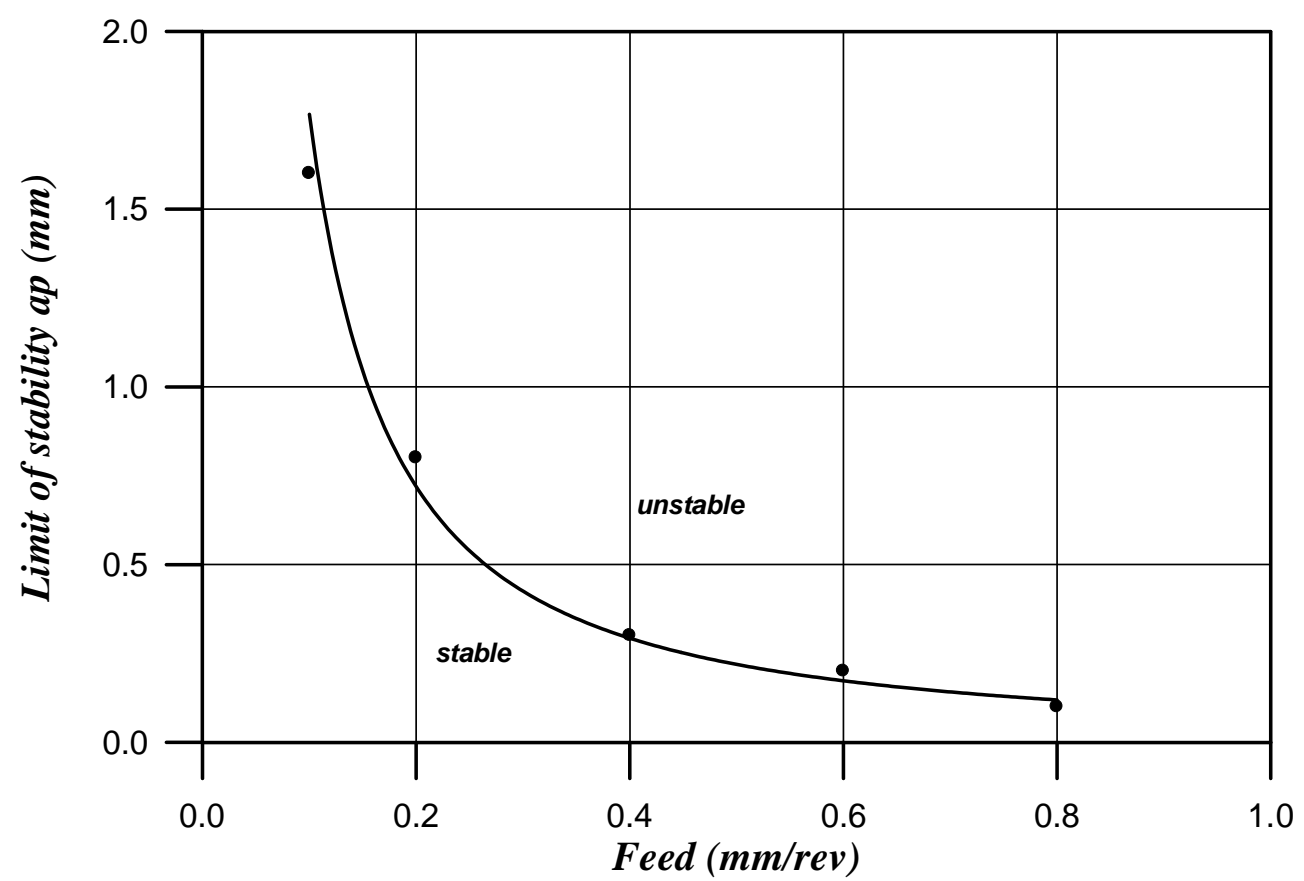

Fig ( 4-b ) the effect of feed rate on the stability limit through cutting the steel with speed (320 r.p.m)

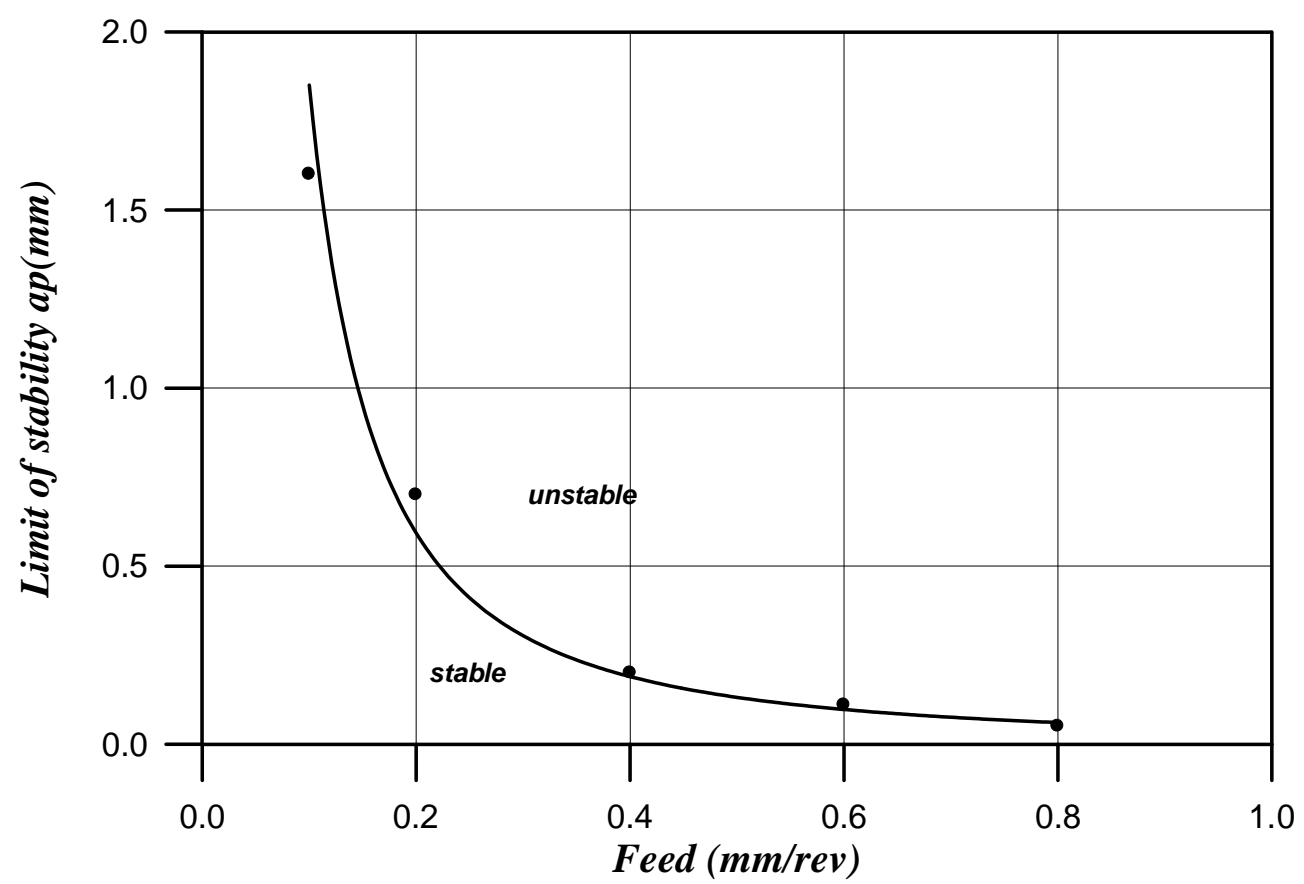

Fig (4-c ) the effect of feed rate on the stability limit through cutting the steel with speed (400 r.p.m) 
$\begin{array}{llll}\text { Al-Rafidain Engineering } & \text { Vol.17 } & \text { No.6 } & \text { Dec. } 2009\end{array}$

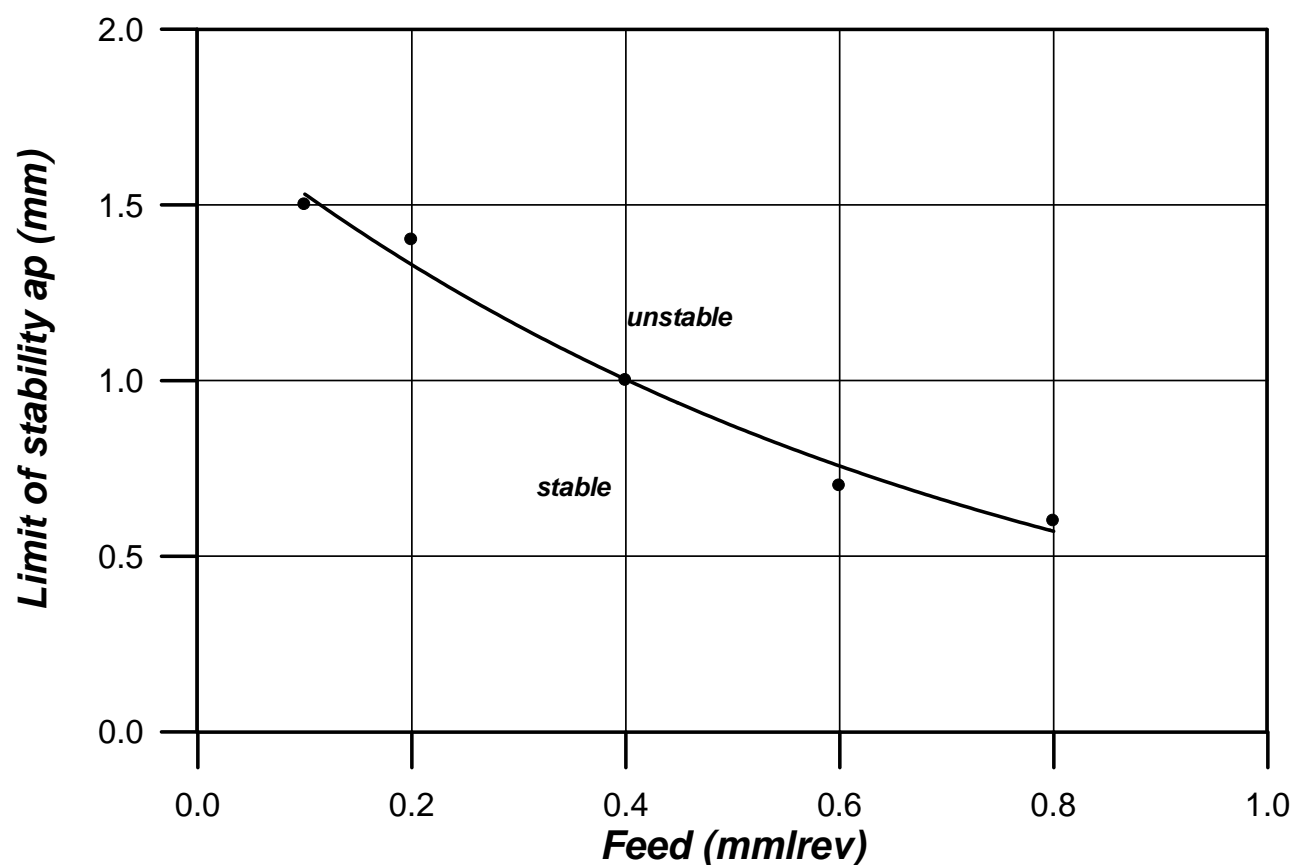

Fig ( 4-d ) the effect of feed rate on the stability limit through cutting the steel with speed (640 r.p.m)

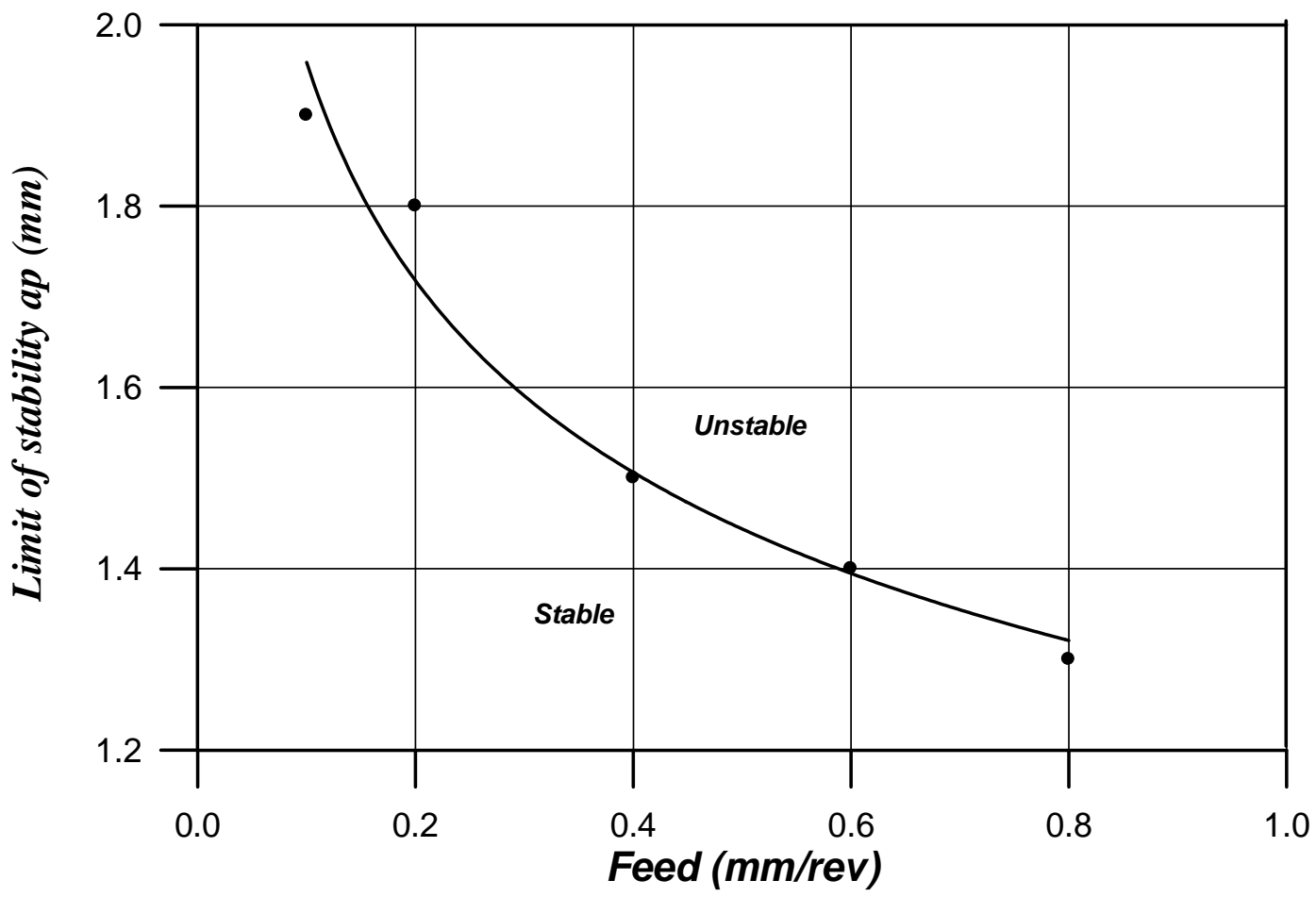

Fig ( 4-e ) the effect of feed rate on the stability limit through cutting the steel with speed (800 r.p.m) 


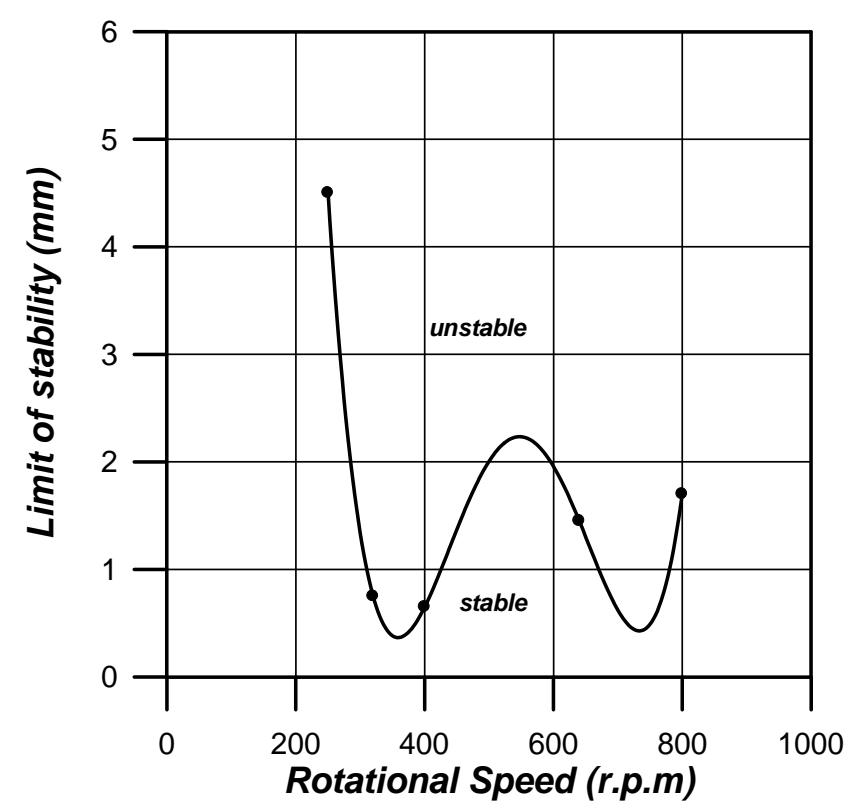

Fig ( 5-a ) the effect of speed on the limit of stability through cutting steel with feed $(0.1 \mathrm{~mm} / \mathrm{rev})$

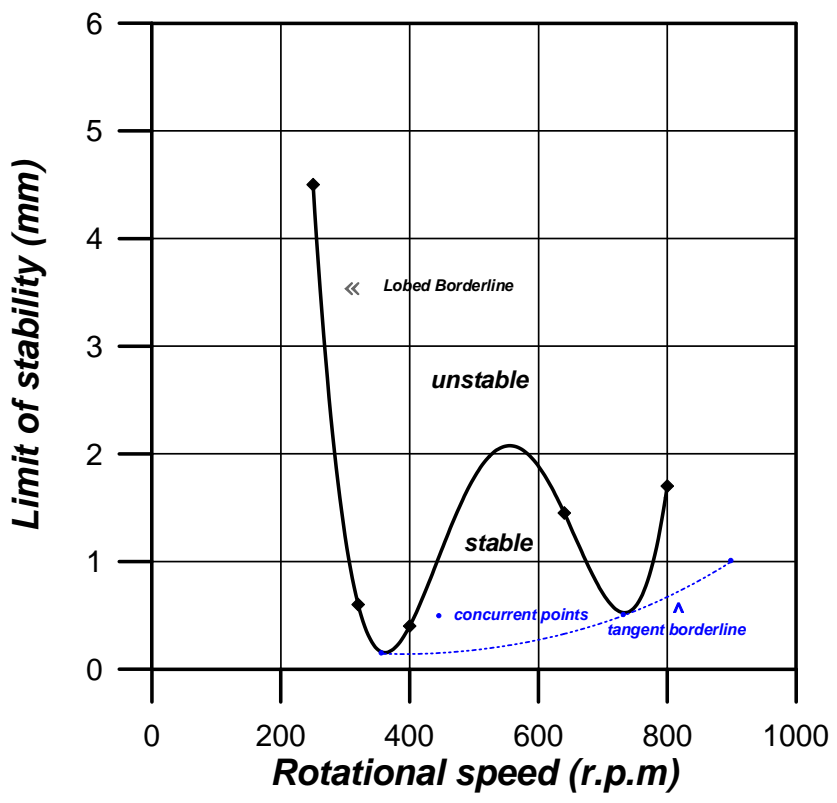

Fig ( 5-b ) the effect of speed on the limit of stability through cutting steel with feed $(0.2 \mathrm{~mm} / \mathrm{rev})$ 
Al-Rafidain Engineering $\quad$ Vol.17 $\quad$ No.6

Dec. 2009

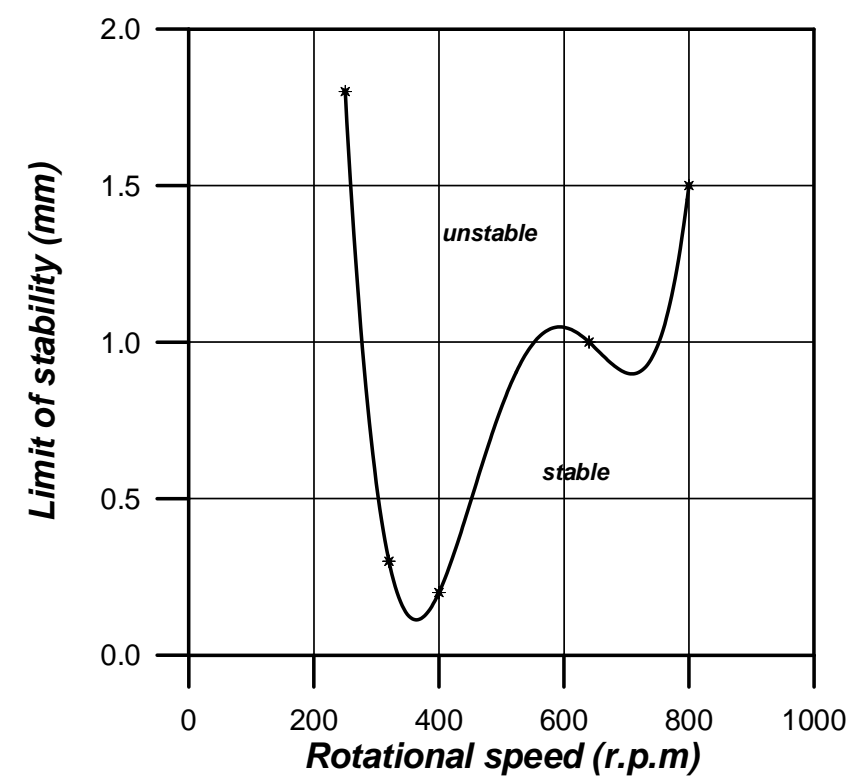

Fig ( 5-c ) the effect of speed on the limit of stability through cutting steel with feed $(0.4 \mathrm{~mm} / \mathrm{rev})$

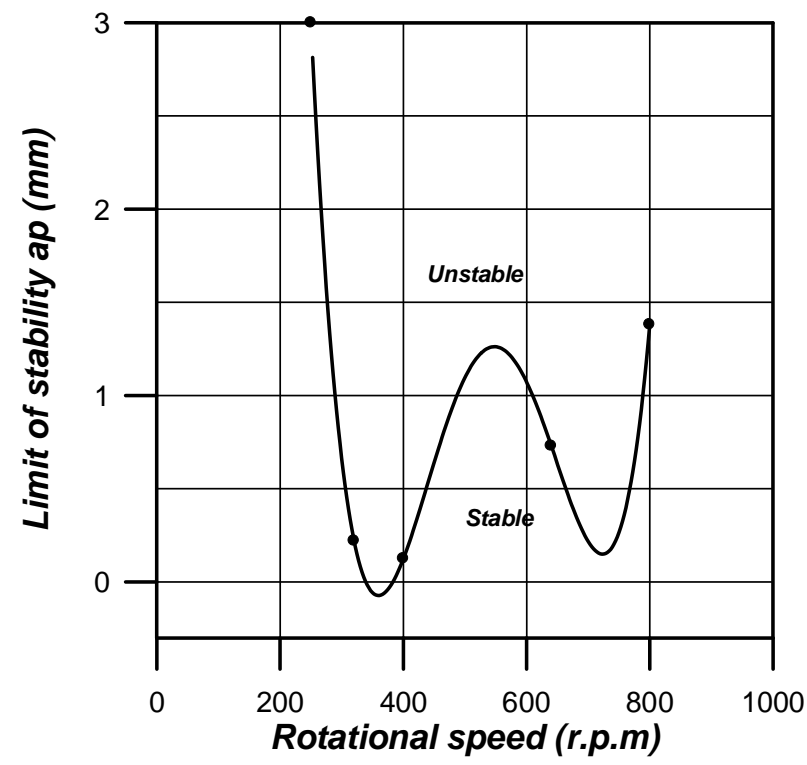

Fig ( 5-d ) the effect of speed on the limit of stability through cutting steel with feed $(0.6 \mathrm{~mm} / \mathrm{rev})$ 


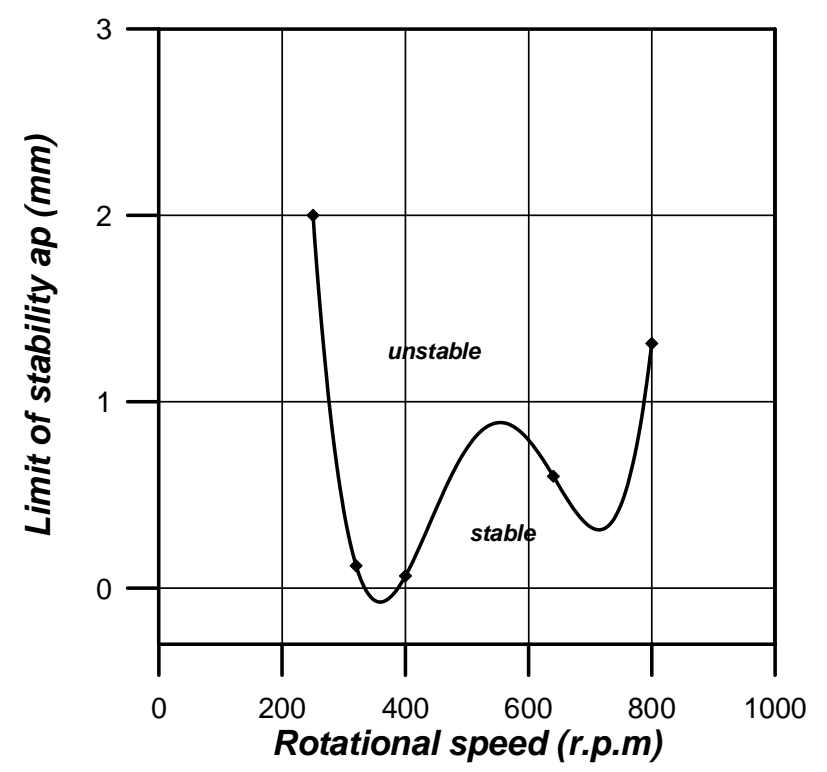

Fig ( 5-e ) the effect of speed on the limit of stability through cutting steel with feed $(0.8 \mathrm{~mm} / \mathrm{rev})$

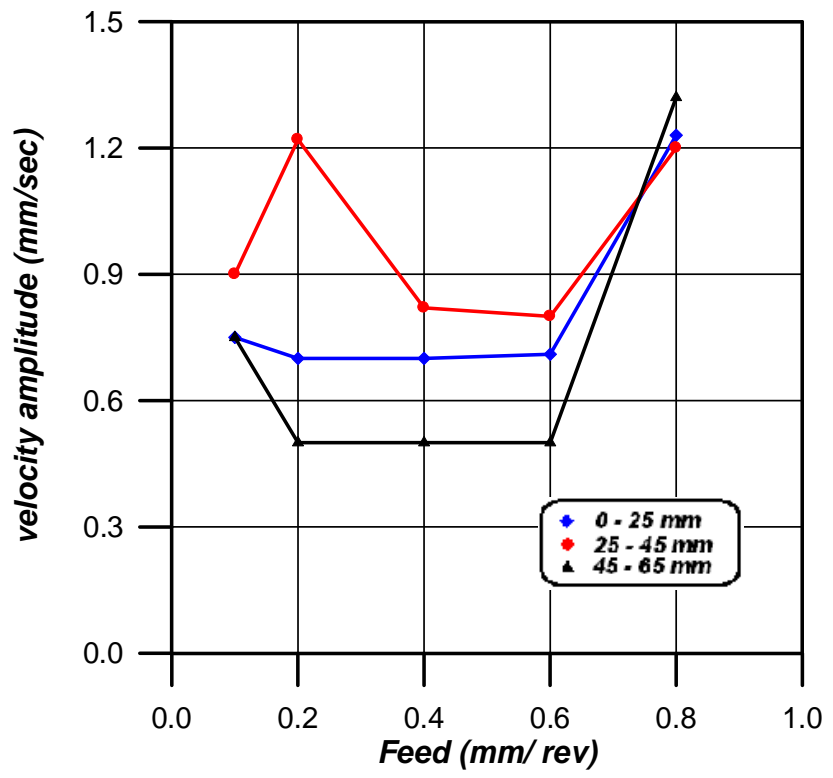

Fig ( 6-a ) effect of feed rate on the vibration amplitude through cutting the steel with $(250 \mathrm{rev} / \mathrm{min})$ and depth of cut $(0.1 \mathrm{~mm})$ 
Al-Rafidain Engineering $\quad$ Vol.17 $\quad$ No.6 $\quad$ Dec. 2009

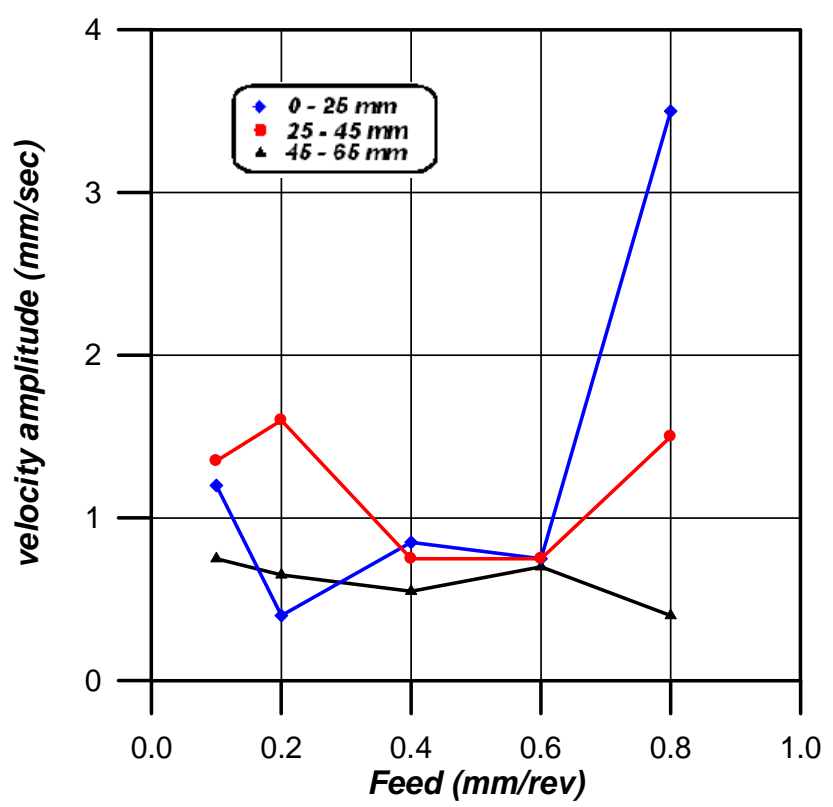

Fig ( 6-b ) effect of feed rate on the vibration amplitude through cutting the steel with $(320 \mathrm{rev} / \mathrm{min})$ and depth of cut $(0.1 \mathrm{~mm})$

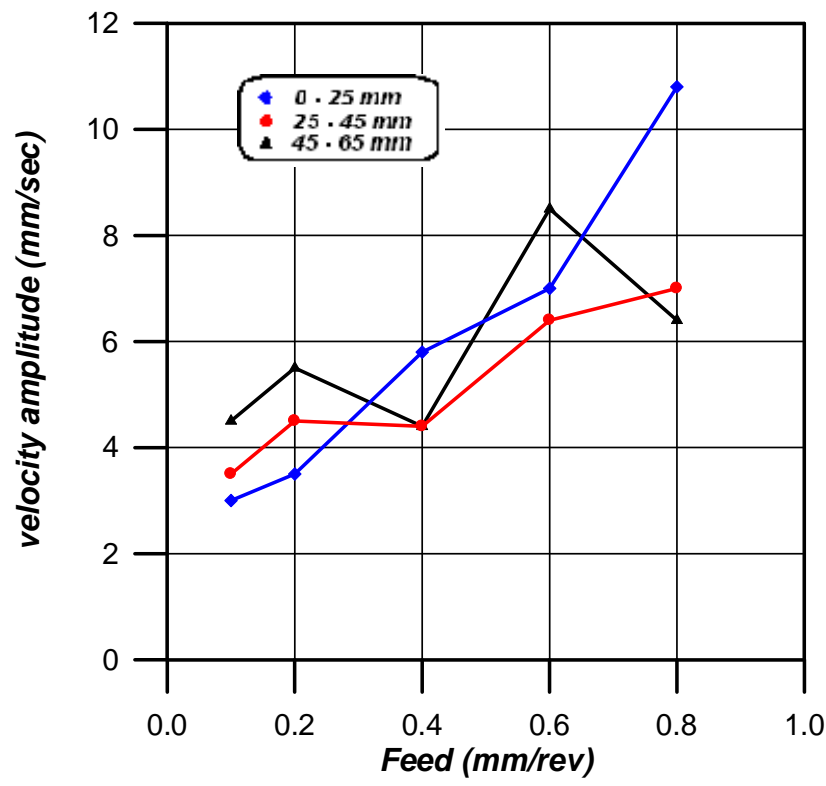

Fig ( 6-c ) effect of feed rate on the vibration amplitude through cutting the steel with (400 rev / min) and depth of cut $(0.1 \mathrm{~mm})$ 


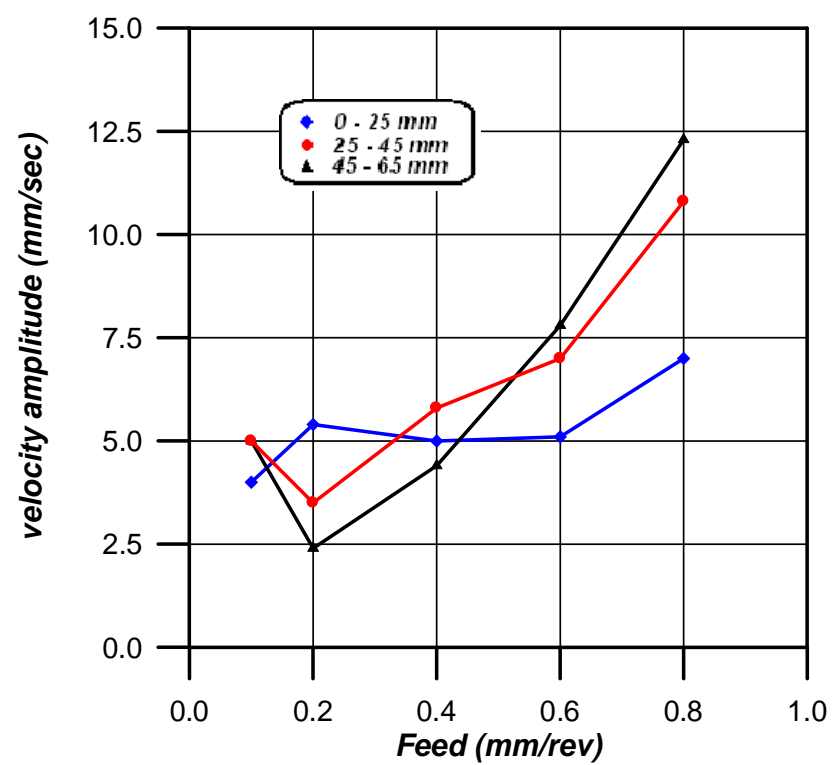

Fig ( 6-d ) effect of feed rate on the vibration amplitude through cutting the steel with $(640 \mathrm{rev} / \mathrm{min})$ and depth of cut $(0.1 \mathrm{~mm})$

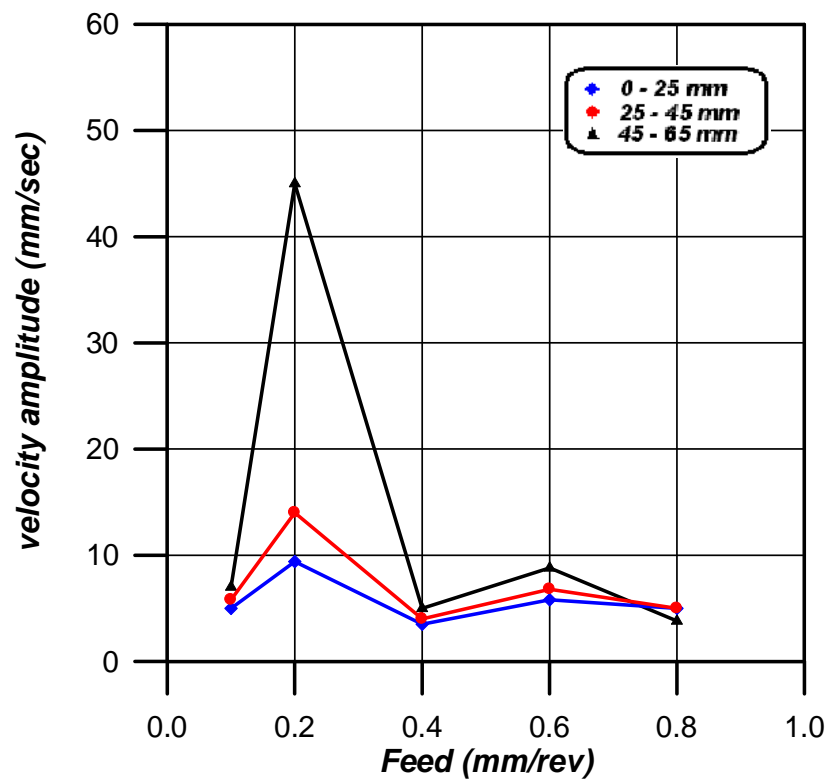

Fig ( 6-e ) effect of feed rate on the vibration amplitude through cutting the steel with $(800 \mathrm{rev} / \mathrm{min})$ and depth of cut $(0.1 \mathrm{~mm})$ 


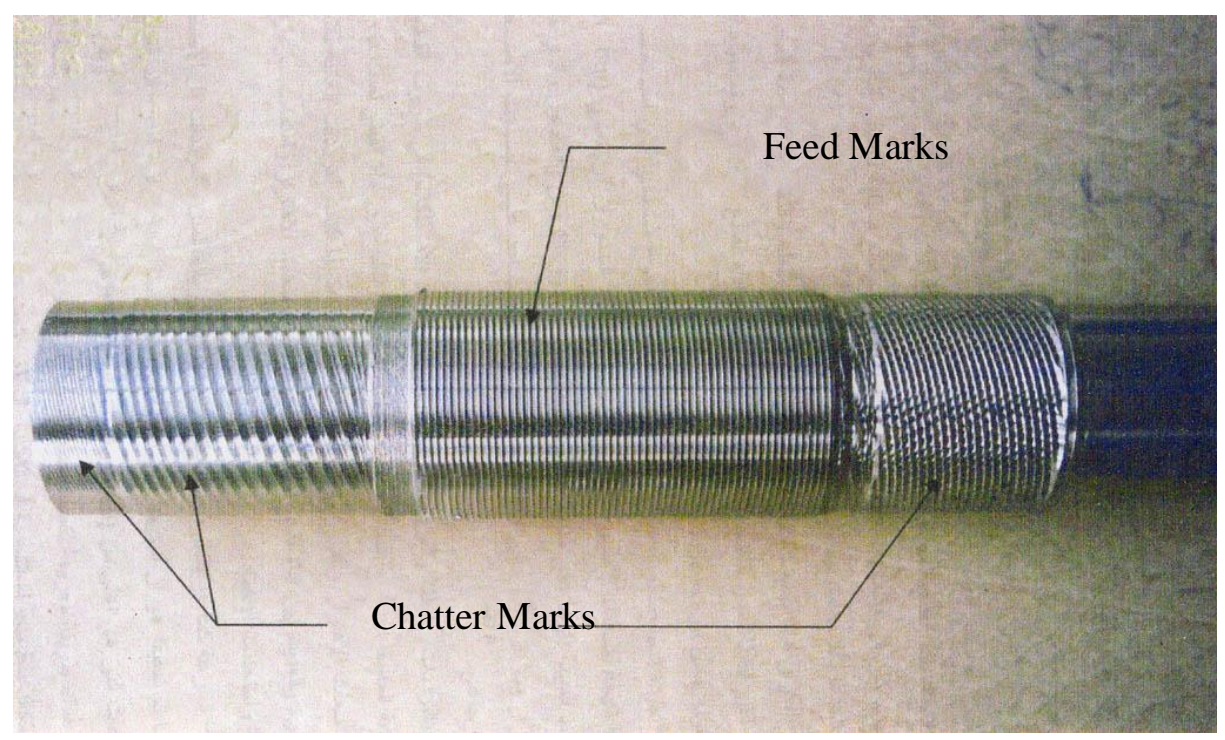

Figure ( 7) The Severity Of Chatter when Cutting Steel AISI1050 ,Showing Chatter and Feed Marks

\section{Conclusion}

Chatter represents the unstable condition initiated during cutting process . Mechanism of the cutting process has a direct influence on products being manufactured and the performance of cutting systems that give an importance to studying the dynamic behavior of all cutting operations and limiting the primary cutting conditions for steady cutting process to overcome chatter. So this study comes up with a number of notes.

1 - To specify the stability limit for different cutting conditions of medium carbon steel

2- Cutting tool vibration seems to be independent of the depth of cut and feed rate for the adopted speed, at small values of depth of cut, vibration is quite enough to separate the cutting tool from its touching with the work piece for the period of each cycle.

3 - Increasing feed rates ,the wavy surface that is created first due to run out of main spindle, the effect of points indicated on lathe machine near chuck, gear box and motor that create vibration which transfer to cutting tool affect the surface quality in bad manner helping to introduce the regenerative chatter.

4- Low frequencies that are close to the natural frequency at a specified speed and the undulations of long waviness increase the vibration amplitude, decreasing the stability of cutting. While the high frequencies of several short waviness between cutting tool and surface decrease the vibration amplitudes, and absorb a fraction of the energy, generating damping .

5- As we know, increasing the speed means increasing the tendency to chatter occurrence ,but what had been achieved, speed share is accomplished a relatively higher stability when cutting with speeds higher than $400 \mathrm{rpm}$ to confirm with [7]. There is no known method to estimate how much change in speed is desire to be applied in order to remove chatter marks other than by doing an experimental investigation under the conditions of workshop .

6- Increasing feed rate had adverse effect which reduces the stability of cutting.

7- Cutting process excite the vibrations in the manufacturing process leading to a damage in the surface quality of the product reducing the cutting tool life . So the attempt to study 
Samarjy : Estimating The Limits of Stability under Several Working Conditions ...

and interpret the mechanism of vibration of all its types represent a basic step to recognize its frequencies and tries to eliminate and reduce it in manufacturing and production systems.

8- At cutting conditions we expect relative displacements between all machine parts that led to variable properties and behaviors of cutting and machine system like creating damping. Difference in stiffness effect the picked response by accelerometer .

9- The transmitted vibrations through the foundation of machine tool in addition to surrounding noise can not be ignored because the picked vibrations are mixture of noise and mechanical vibrations as a result of no filter is used in system to isolate the noise as in using the vibration analyzer.

10-The unhomogenity of microstructure of steel being used affects the picked responses

\section{References}

1. Bruel \& Kjaer, Short form catalogue "Sound, Vibration and Signal Analysis Instrumentation " English DK 1981

2. C. R .Liu \& T. M.Liu (Automated Chatter Suppression by Tool geometry Control), Journal of Engineering for Industry ASME . Vol .107/96 May 1985.

3. D. W. Wu,\& C .R.Liu., " An Analytical Model of Cutting Dynamic .Part 1 : Model Building, Journal Of Engineering for Industry, May 1985, Vol.107/111.

4. Geoffrey Boothroyd " Fundamentals of Metal Machining and Machine Tools"

5. Hindustan machine tools LTD "Operators and maintenance manual ", Hindustan Centre lathe LB17, LB 20 , and LB25.

6. H . B. Lacerda and V.T.Lima "Evaluation of Cutting Forces and Prediction Of Chatter Vibrations in Milling. Journal Of Braz . Soc. Of Mech. Sci .\& Eng. JanuaryMarch 2004 , Vol xxvi, No.1 / 81.

7. Jain . K .C \& Aggarwal .L.N “ Metal Cutting Science \& Production Technology” .Khanna publishers ,-Delhi -1968. chapter $(1,12,13)$.

8. M. Rahman \& Y. Ito " Detection Of the Onset Of Chatter Vibration ", Journal of Sound and Vibration .1986, Vol 109(2), 193 - 205.

9. S .S. Rao 1995 Mechanical Vibrations ,p.572. New York : Addison - Wesley.

The work was carried out at the college of Engg. University of Mosul 